It is commonly assumed that 'white horses' are due to the wind blowing off the tops of the primary waves, and that may be partly true. But they are apt to persist for some time after the wind has completely dropped, so must also be accounted for by the steepening, and consequent breaking, of secondary waves when the crests of the primary ones are passing under them. To reduce the problem to figures, let $L, H, S$ be $200 \mathrm{ft} ., 5 \mathrm{ft}$. and 0.025 , and let $l, h, s$ be $20 \mathrm{ft} ., 2 \mathrm{ft}$. and $0 \cdot 10$, on the average. $s$ will increase from that average value to almost 0.12 , which is not far off Wilton's theoretical limit ${ }^{1}$ of $0 \cdot 13$, a figure which may not necessarily always be attained, for waves have but a small margin of stability as they approach breaking point.

Further, it seems to be common experience that a nasty lop gets up with great rapidity when wind starts to blow' against a swell, and this may be accounted for by the effect described.

The above applies to deep water. When the primary waves run into shoal water, the horizontal movement of the water particles is increased, and so the length and height of secondary waves, when they are riding on primary crests, are respectively decreased and increased to greater extents than before. There will only be secondary waves when there is an onshore wind, and then these waves will break more easily after the primary ones feel the bottom than they did before; and when they do break they will create disturbances which may initiate the breaking of the primary waves. This may be an explanation of the conclusion arrived at by Gaillard ${ }^{2}$, who made many observations to determine the ratio of $D$ (depth of water) to $H$ necessary to cause breaking. He found that "for a given locality and given slope [of bottom] variations in the ratio of $D$ to $H$ appeared to be due almost entirely to the direction and force of the wind", and that while with a strong onshore wind the ratio might be 1.25 , an offshore wind reduced the figure to $0 \cdot 72$.

P. J. H. UNNA.

4 Dean's Yard,

London, S.W.1.

${ }^{1}$ Phil. Mag., (6) 23, 1055 (1913).

2 Gaillard, "Wave Action in relation to Engineering Structures", p. 120 .

\section{Transmission of Leishmania tropica by the Bite of Phlebotomus papatasii}

SANDFlies Phlebotomus papatasii 우 were infected with Leishmania tropica by feeding through a membrane on a susponsion of flagellates in 3 parts of $2 \cdot 7$ per cent saline and 1 part inactivated defibrinated rabbit blood.

They were afterwards refed on eight human volunteers, of whom five have so far become infected with cutaneous leishmaniasis as a result of bites from twenty-six infected sandflies. Twenty-six infected sandflies produced twenty-eight individual lesions, of which twenty-seven were produced by eleven sandflies only.

This experiment differed from previous negative experiments only in that the sandflies were kept at a temperature of $30^{\circ} \mathrm{C}$. and that they were infected by feeding on a suspension containing $2 \cdot 7$ per cent saline instead of normal physiological saline. Full details will be published elsewhere.

Department of Parasitology,

Hebrew University,

S. Adler. Jerusalem.

\section{Evolution in the Genus Pronia}

T'HE genus Pæonia has three main centres of distribution and diversity : in the Mediterranean and Black Sea basins, in the Far East from Tibet to Japan, and in North America. From my own and previous chromosome studies ${ }^{1,2,3}$, I find that in these separate regions it has undergone three different methods of species formation, all the time working with the same haploid set of five chromosomes.

In the Mediterranean area are a group of smallrange diploids $(2 n=10)$. Most of these diploids, apparently by simple doubling, have given rise to large-range tetraploids $(2 n=20)$ usually lying to the north of their progenitors. Three of these large-range tetraploids, namely, arietina and peregrina in the Balkans and Asia Minor, and coriacea in southern Spain and Morocco, have no nearly related diploids ; apparently their ancestors have failed to survive (see accompanying table).

\section{Species IN Panonia}

$2 x$ $4 x$

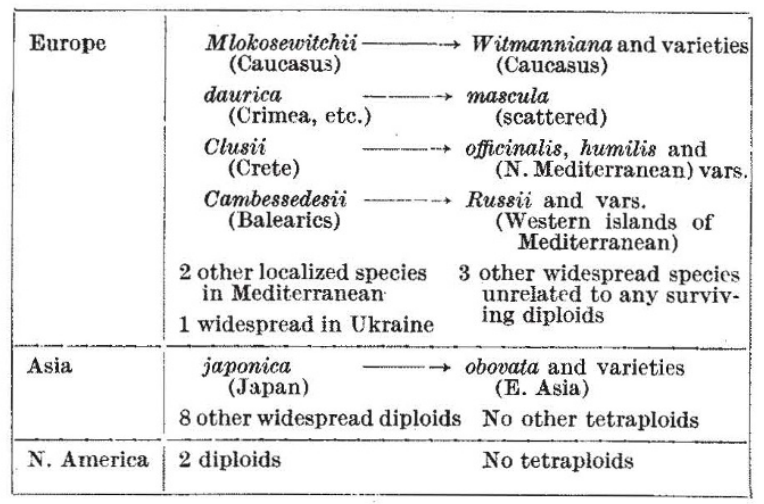

It thus seems that the advancing ice had driven the diploid species into Mediterranean peninsulas and islands, and from these isolated fragments of pre-glacial species Europe was afterwards recolonized by more vigorous, or perhaps more adaptable, tetraploids as the ice retreated. The kind of adaptability is shown in some cases to consist in stronger tuber development.

In Asia, on the other hand, there has been no such impassable barrier to movement back and forth, and we find a number of diploid species-some covering a large range, for example, $P$. lactiflora and $P$. anomala - and only one tetraploid, $P$. obovata. This species again is in the north (Manchuria and eastern Siberia), but it seems that the diploids, never having been restricted in population and variation, have themselves been able to meet the opportunity of colonization and to follow the retreating ice northwards.

In the smaller territory of California and Oregon a smaller population shows yet another system of variation. Only two species are recognized, and both of them are true-breeding diploid hybrids of the kind known in Enothera. Instead of having five bivalents at meiosis they have rings of six, eight or ten chromosomes $^{3}$.

Thus in the three regions Nature seems to have carried out an experiment in variation and selection which helps us to understand how different conditions, partly external and partly perhaps internal, can lead to different methods of evolution in members of one genus. 